\title{
Targeting Hsp90 with small molecule inhibitors induces the over-expression of the anti-apoptotic molecule, survivin, in human A549, HONE-1 and HT-29 cancer cells
}

\author{
Chun Hei Antonio Cheung ${ }^{1}$, Huang-Hui Chen ${ }^{+1}$, Li-Ting Cheng ${ }^{+1}$, Kevin W Lyu², Jagat R Kanwar ${ }^{3}$ and Jang- \\ Yang Chang*1,4
}

\begin{abstract}
Background: Survivin is a dual functioning protein. It inhibits the apoptosis of cancer cells by inhibiting caspases, and also promotes cancer cell growth by stabilizing microtubules during mitosis. Since the molecular chaperone Hsp90 binds and stabilizes survivin, it is widely believed that down-regulation of survivin is one of the important therapeutic functions of Hsp90 inhibitors such as the phase III clinically trialed compound 17-AAG. However, Hsp90 interferes with a number of molecules that up-regulate the intracellular level of survivin, raising the question that clinical use of Hsp90 inhibitors may indirectly induce survivin expression and subsequently enhance cancer anti-drug responses. The purpose of this study is to determine whether targeting Hsp90 can alter survivin expression differently in different cancer cell lines and to explore possible mechanisms that cause the alteration in survivin expression.

Results: Here, we demonstrated that Hsp90 inhibitors, geldanamycin and 17-AAG, induced the over-expression of survivin in three different human cancer cell lines as shown by Western blotting. Increased survivin mRNA transcripts were observed in 17-AAG and geldanamycin-treated HT-29 and HONE-1 cancer cells. Interestingly, real-time PCR and translation inhibition studies revealed that survivin was over-expressed partially through the up-regulation of protein translation instead of gene transcription in A549 cancer cells. In addition, 17-AAG-treated A549, HONE-1 and HT-29 cells showed reduced proteasomal activity while inhibition of $26 \mathrm{~S}$ proteasome activity further increased the amount of survivin protein in cells. At the functional level, down-regulation of survivin by siRNA further increased the drug sensitivity to 17-AAG in the tested cancer cell lines.

Conclusions: We showed for the first time that down-regulation of survivin is not a definite therapeutic function of Hsp90 inhibitors. Instead, targeting Hsp90 with small molecule inhibitors will induce the over-expression of survivin in certain cancer cell lines and subsequently enhances the ability of cell survival in drug-treated situations. The current study suggests that dual inhibition of Hsp90 and survivin may be warranted.
\end{abstract}

\section{Introduction}

Heat shock protein 90 (Hsp90) is a molecular chaperone that assists the correct folding and stabilization of various proteins in cells. During the last decade, Hsp90 has emerged as an exciting target for cancer therapy. The over-expression of Hsp90 has been shown in various can-

\footnotetext{
* Correspondence: jychang@nhri.org.tw

1 National Institute of Cancer Research, National Health Research Institutes (NHRI), Tainan 70456, Taiwan ROC

+ Contributed equally

Full list of author information is available at the end of the article
}

cers such as non-small cell lung cancer, oesophageal squamous cell carcinoma, pancreatic carcinoma and advanced malignant melanoma [1-4]. In addition, studies showed that Hsp90 stabilizes various key oncogenic proteins such as survivin, Akt, Erb-2 and HIF-1 $\alpha$ in cancer cells [5-7]. Therefore, targeting hsp90 gives therapeutic advantages over other target-therapies as multiple Hsp90-related oncogenic proteins can be targeted simultaneously [7]. 
Survivin is a member of the inhibitors of apoptosis (IAPs) family. Unlike other IAPs, survivin is a bifunctional protein that functions as a key regulator of mitosis and inhibitor of programmed cell death. It is well-demonstrated that the over-expression of survivin induces resistance to various anti-cancer therapies such as chemotherapy and radiation therapy in cancer cells [812]. For example, over-expression of survivin has been shown to induce drug resistance against anti-mitotic compounds by stabilizing microtubule network in vincristine/colchicine-resistant oral cancer cells and downregulation of it restores drug sensitivity to those compounds in the same cell line [9]. In addition, literature revealed that over-expression of survivin attenuated both tamoxifen and cisplatin-induced apoptosis in human breast cancer cells and gastric cancer cells respectively $[10,12]$. Interestingly, a recent report suggests that overexpression of survivin may also enhance DNA doublestrand breaks (DBD) repair capability in radiation-treated oral cancer cells by up-regulating the molecular sensor of DNA damage, Ku70 [11]. In clinical situations, the level of survivin expression was shown to be inversely related to the levels of apoptosis and positively related to the risk of local tumor recurrence in rectal cancer patients treated with radiotherapy [13]. Furthermore, patients with gastric tumors that express lower level of survivin seems to have a longer mean survival time than patients with higher survivin expression level after cisplatin treatment [12]. It has also been shown that survivin expression is associated with human prostate cancer bone metastasis [14]. Thus, survivin plays an important role in tumorigenesis, tumor metastasis and may act as an indicator of therapeutic effectiveness.

It is widely believed that Hsp90 physically interacts and stabilizes survivin in cells $[5,15,16]$. Although Hsp90 is a molecular chaperone that assists the correct folding of various proteins in cells, it does not bind to unfolded survivin [5]. Instead, Hsp90 binds to the mature form of survivin [5]. Structurally, the amino acid sequence Lys-70Lys-90 of survivin is important for the binding to the $\mathrm{N}$ terminal domain (ATP-binding site) of Hsp90 [5]. Various studies have investigated the possibility of targeting survivin using Hsp90 inhibitors, based on the fact that survivin is important for cancer survival and progression. Hsp90 inhibitors such as geldanamycin, 17-AAG and shepherdin have been shown effective in targeting the Hsp90/survivin complex and subsequently inducing proteasomal degradation of survivin [5,16-18].

Although it is widely believed that Hsp90 inhibitors induce cancer cell death through indirect down-regulation of survivin as one of its multiple therapeutic functions, a study demonstrated that 17-AAG treatment slightly increased the amount of survivin present in the human DU145 prostate cancer cells [7]. However, the mechanism of the over-expression of survivin in such cell line was unknown. Interestingly, we also observed an upregulation of survivin in 17-AAG and geldanamycintreated human A549, HONE-1 and HT-29 cancer cells. Since Hsp90 interferes with multiple molecules such as sp1, sp3 (both transcriptional factors of survivin), and $26 \mathrm{~S}$ proteasome (negative regulator of survivin protein level) simultaneously $[19,20]$, we hypothesize that targeting Hsp90 will affect the expression of survivin at various stages. We also hypothesize that the use of Hsp90 inhibitors may not be able to down-regulate survivin expression in certain cancer cells. Therefore, the purpose of this study is to determine whether targeting Hsp90 can alter survivin expression differently in different cancer cell lines and to explore possible mechanisms that cause the alteration in survivin expression.

\section{Results}

Targeting Hsp90 induces the over-expression of survivin in cancer cells

To determine whether the inhibition of Hsp90 with small molecule inhibitors was able to affect survivin expression, we treated human cancer cells with Hsp90 inhibitors geldanamycin and 17-AAG. 17-AAG is a selective Hsp90 inhibitor that exhibited therapeutic activities in various cancers and is currently undergoing phase III clinical trials [17,21-24]. To ensure that both of our selected Hsp90 inhibitors were functioning normally at the molecular level, HeLa cells (positive control) were incubated with 17-AAG and geldanamycin for $24 \mathrm{~h}$ and Western blot analysis was used to determine the amount the survivin presented in cells. Consistent with other studies, targeting Hsp90 with 17-AAG and geldanamycin (100 nM, 250 $\mathrm{nM}$ and $500 \mathrm{nM}$ ) reduced the amount of survivin expressed in HeLa cells (Figure 1A) [5]. The effectiveness of Hsp90 inhibitors was subsequently tested with the use of the three-dimensional cell culturing system. Western blot analysis revealed that the expression of survivin was also down-regulated in three-dimensionally cultured HeLa cells treated with $1 \mu \mathrm{M}$ of $17-\mathrm{AAG}$ for $24 \mathrm{~h}$ (Additional file 1).

To determine whether Hsp90 inhibitors were able to down-regulation survivin in other cancer cell lines, human A549, HT-29 and HONE-1 cancer cells were used. In A549 cells, targeting Hsp90 with 17-AAG and geldanamycin slightly induced the baseline expression of Hsp90 as previously reported (Figure 1B) [5]. The same treatment also induced down-regulation of both Akt and phosporylated-Erk in human A549 (p53-mutant) lung carcinoma cells as expected (Figure 1B) [7,25]. Together, these results indicated that both Hsp90 inhibitors were functioning normally at the molecular level. Surprisingly, targeting Hsp90 with 17-AAG and geldanamycin did not induce survivin down-regulation in A549 cancer cells. 


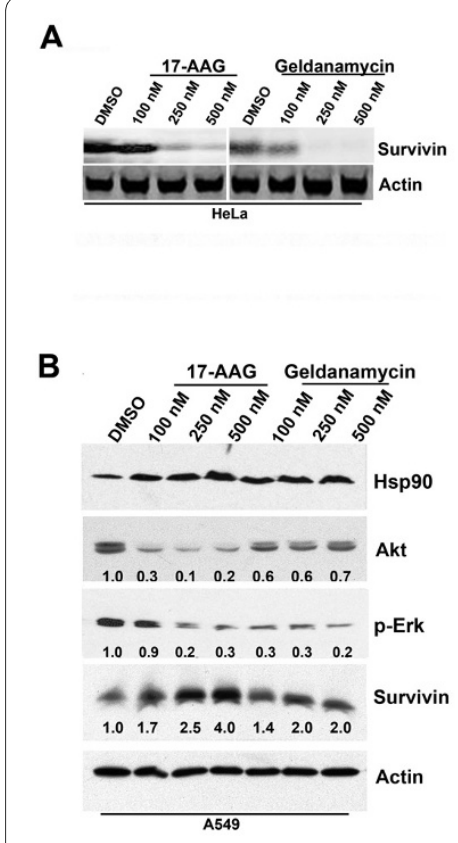

C

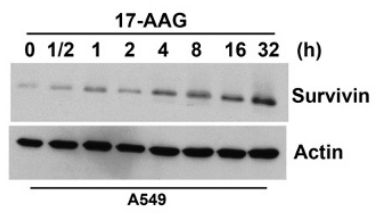

Figure 1 Inhibition of Hsp90 with small molecule inhibitors induces survivin over-expression in human A549 cancer cells. (A) Concentration-dependent down-regulation of survivin in drug-treated human HeLa cancer cells. HeLa cells were treated with DMSO or various concentrations (100 nM, $250 \mathrm{nM}$ and $500 \mathrm{nM}$ ) of 17-AAG and geldanamycin for 24 hours. Cell lysate was prepared after the treatment and various proteins were resolved by SDS-PAGE. (B) Concentration-dependent over-expression of survivin in drug-treated human A549 cancer cells. A549 cells were treated with DMSO or various concentrations (100 nM, $250 \mathrm{nM}$ and $500 \mathrm{nM}$ ) of 17-AAG and geldanamycin for 24 hours. Cell lysate was prepared after the treatment and various proteins were resolved by SDS-PAGE. The expression of Hsp90, Akt, phosphorylated-Erk and survivin was revealed by Western blot analysis. Actin was used as an internal control. Relative ratios of expression were shown. (C) Time-dependent over-expression of survivin in drug-treated human A549 cancer cells. Human A549 cells were treated with 500 nM of 17-AAG for various intervals. Cell lysate was prepared after the treatment and various proteins were resolved by SDS-PAGE. The expression of survivin was revealed by Western blot analysis. Actin was used as an internal control. (D) Over-expression of survivin in human A549 cells treated with high concentrations of 17-AAG. A549 cells were treated with 1-2 $\mu \mathrm{M}$ of 17-AAG for 24 hours. Cell lysate was extracted after the treatment and various proteins were resolved by SDSPAGE. Relative ratios of expression were shown.

Instead, Western blot analysis revealed that survivin expression was induced by Hsp90 inhibitors in A549 cells in a concentration-dependent manner (Figure 1B). In addition, over-expression of survivin was shown in cells treated with 17-AAG in a time-dependent manner (Figure $1 C$ ). Since clinical study of 17-AAG revealed that the maximum peak serum level of this compound could reach 2-3 $\mu \mathrm{M}$, A549 cells were further treated with high concentrations of 17-AAG and the expression of survivin was determined. Over-expression of survivin was also found in A549 cells treated with high concentrations (1 $\mu \mathrm{M}$ and $2 \mu \mathrm{M}$ ) of 17-AAG (Figure 1D). Moreover, Western blot analysis revealed that the expression of survivin was up-regulated in three-dimensionally cultured A549 cells treated with $1 \mu \mathrm{M}$ of 17 -AAG for $24 \mathrm{~h}$ (Additional file 1).

The expression of survivin in Hsp90 inhibitors-treated HONE-1 and HT-29 cells was determined by Western blotting. Western blot analysis revealed that both $17-$ AAG and geldanamycin treatments were able to induce the over-expression survivin in HONE-1 (p53 wildtype) nasopharyngeal carcinoma cells in a concentrationdependent manner (Figure 2A). 17-AAG or geldanamycin treated HT-29 (p53 mutant) colon adenocarcinoma cells also over-expressed survivin (Figure $2 \mathrm{~B}$ ). In contrast, 17-AAG treatment was able to reduce the expression of
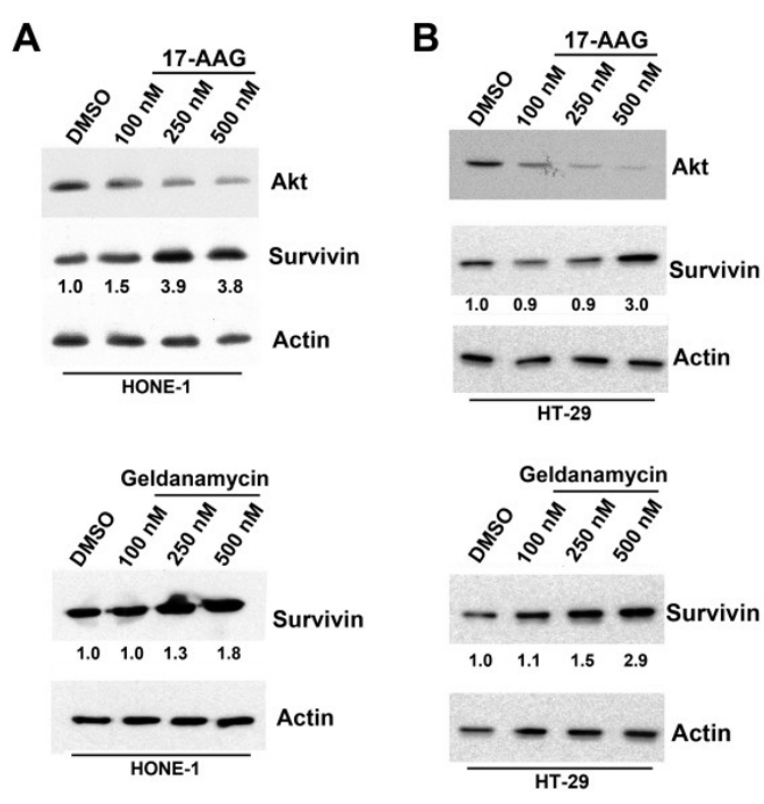

Figure 2 Over-expression of survivin in various 17-AAG/geldanamycin-treated human cancer cell lines. (A) Human HONE-1 cancer cells were treated with various concentrations of 17-AAG/geldanamycin for 24 hours. Cell lysate was prepared after the treatment and various proteins were resolved by SDS-PAGE. The expression of Akt and survivin was revealed by Western blot analysis. Actin was used as an internal control. Relative ratio of expression was shown. (B) Human HT29 cancer cells were treated with various concentrations of 17-AAG/ geldanamycin for 24 hours. Cell lysate was prepared after the treatment and various proteins were resolved by SDS-PAGE. The expression of Akt and survivin was revealed by Western blot analysis. Actin was used as an internal control. Relative ratio of expression was shown. 
Akt in a concentration-dependent manner as previously reported (Figures $2 \mathrm{~A}$ and $2 \mathrm{~B}$ ) $[7,25]$. Taken together, these data indicate that the surprising effect of Hsp90 inhibitors were specific to survivin in this study, as 17AAG and geldanamycin did not modulate the expression of Hsp90, Akt and phosphorylated-Erk in A549 cells and the expression of Akt in HONE-1 and HT-29 cells differently compared to the results of other studies. In threedimensional culture situations, Western blot analysis revealed that 17-AAG treatment increased the amount of survivin presented in HONE-1 and HT-29 cells (Additional file 1). These results suggest that down-regulation of survivin is not a definite therapeutic effect induced by Hsp90 inhibitors, as over-expression of survivin was observed in cells treated with 17-AAG and geldanamycin in this study.

\section{Targeting Hsp90 induces the over-expression of survivin through a cell-cycle independent mechanism}

It has been widely demonstrated that the expression of survivin is tightly regulated during cell cycle and maximized during the $\mathrm{G}_{2} / \mathrm{M}$ phase. To determine whether the over-expression of survivin in Hsp90-targeted cells was a downstream result caused by cell cycle arrest at the $G_{2} / M$ phase, flow cytometric analysis was performed. Interestingly, 17-AAG treatment did not induce a uniform cell cycle response among A549, HONE-1 and HT-29 cells. Experimental results demonstrated that $500 \mathrm{nM}$ of 17AAG induced cell cycle arrest of A549 cells at the $G_{2} / M$ phase after $24 \mathrm{~h}$ (Figure 3). In contrast, the same treatment induced $S$-phase arrest and $G_{0} / G_{1}$ phase cell cycle arrest in HONE-1 and HT-29 cells respectively (Figure 3). Taken together, results from both Western blot analysis and flow cytometric analysis indicated that changes in survivin expression in Hsp90-targeted cells were not downstream results caused by cell cycle arrest at the $G_{2} /$ M phase.

\section{Targeting Hsp90 affects survivin expression at the transcriptional level}

Since 17-AAG induced over-expression of survivin was not an indirect result caused by cell cycle arrest, detailed molecule mechanisms that govern survivin over-expression were investigated. It is widely believed that the amount of protein presented in cells is tightly regulated through the process of gene transcription, protein translation and protein degradation. To determine whether the over-expression of survivin in Hsp90 inhibitor-treated A549, HONE-1 and HT-29 cells was caused by changes at the level of gene transcription, quantitative real-time PCR was performed after $24 \mathrm{~h}$ post-treatment. In contrast to the result of Western blot analysis, a dose-dependent decrease in the amount of survivin mRNA transcript in 17-AAG-treated A549 cells was shown by real-time
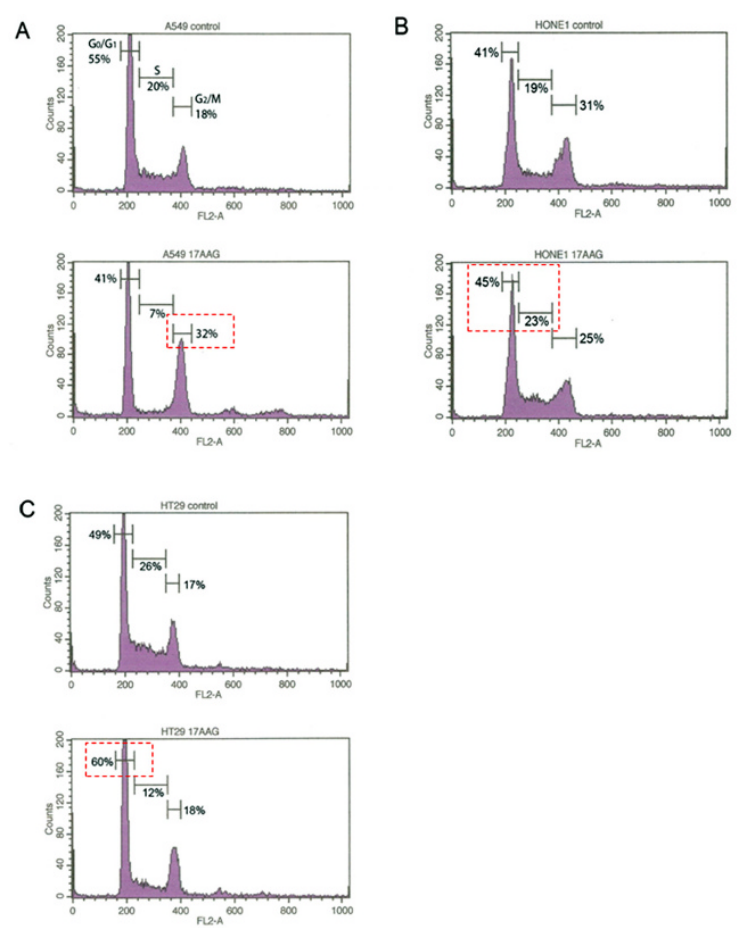

Figure 3 17-AAG induces the over-expression of survivin through cell cycle-independent mechanism. A549 (A), HONE-1 (B) and HT29 (C) cells treated with $500 \mathrm{nM}$ of 17-AAG for $24 \mathrm{~h}$ were stained with propidium iodide and subsequent analyzed by flow cytometry. Major changes in the cell cycle of 17-AAG-treated cells were highlighted in red color

PCR (Figure 4A). A general decrease in the amount of survivin mRNA transcript was also shown in geldanamycin-treated cells (Figure 4A). Cells treated with geldanamycin and 17-AAG showed reduced amount of survivin mRNA by $45 \%(500 \mathrm{nM})$ and $75 \%(500 \mathrm{nM})$ respectively in A549 cells, as compared to the control (Figure 4A). However, phase-contrast microscopy did not reveal morphological signs of death in Hsp90 inhibitors-treated cells (Figure 4B). Therefore, both geldanamycin and 17-AAG induced decreases in survivin mRNA instead of cell death-induced global decreases at the total intracellular mRNA level. These results also indicated that 17-AAG/ geldanamycin treatment increased the level of survivin protein in cells possibly through transcription-independent mechanism in A549 cancer cells. In contrast, 17AAG and geldanamycin treatment did not decrease the amount of survivin RNA transcript present in HT-29 and HONE-1 cells (Figure 4C and 4D). Instead, the same treatment increased the level of survivin RNA in cells in a dose-dependent manner. Thus, the effect induced by Hsp90 inhibitors on the level of survivin gene transcription seems to depend on the cellular context. Furthermore, the results suggest that increases in survivin protein in response to Hsp90-targeted therapy in HT-29 
A

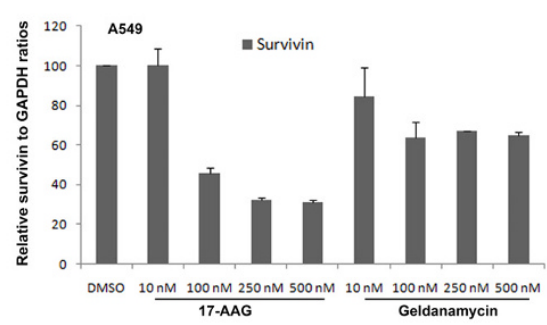

B

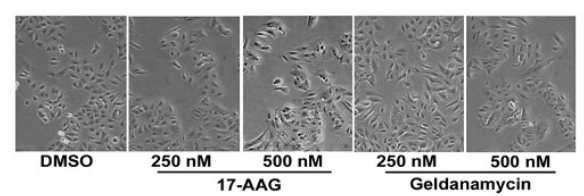

C

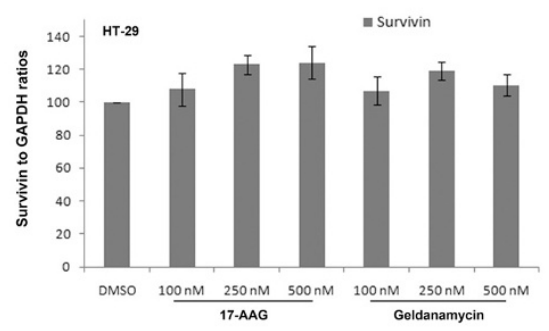

D

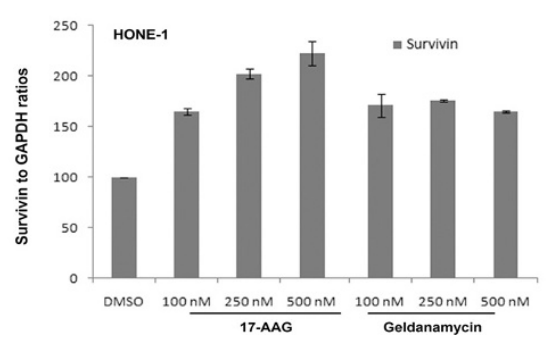

Figure 4 17-AAG treatment induces over-expression of survivin through transcription-independent mechanisms. (A) Inhibition of Hsp90 reduced the amount of survivin mRNA transcript presented in 17-AAG treated A549 cells. Human A549 cancer cells were incubated with DMSO (negative control) or various concentrations ( $10 \mathrm{nM}, 100$ $\mathrm{nM}, 250 \mathrm{nM}$ and $500 \mathrm{nM}$ ) of 17-AAG and geldanamycin for 24 hours. Quantitative RT-PCR was performed to determine the amount of survivin transcripts presented in cells. (B) Cells treated with 17-AAG and geldanamycin did not induce abnormal cell morphology. A549 cells incubated with various concentrations ( $250 \mathrm{nM}$ and $500 \mathrm{nM}$ ) of 17AAG and geldanamycin for 24 hours and cell morphology was revealed by phase-contrast microscopy. (C) Inhibition of Hsp90 increased the amount of survivin mRNA transcript presented in 17-AAG and geldanamycin treated HT-29 cells. HT-29 cells were incubated with DMSO (negative control) or various concentrations (10 nM, 100 $\mathrm{nM}, 250 \mathrm{nM}$ and $500 \mathrm{nM}$ ) of 17-AAG for 24 hours. Quantitative RT-PCR was performed to determine the amount of survivin transcripts presented in cells. (D) Inhibition of Hsp90 increased the amount of survivin mRNA transcript presented in 17-AAG treated HONE-1 cells.

HONE-1 cells were incubated with DMSO (negative control) or various concentrations ( $10 \mathrm{nM}, 100 \mathrm{nM}, 250 \mathrm{nM}$ and $500 \mathrm{nM}$ ) of 17-AAG for 24 hours. Quantitative RT-PCR was performed to determine the amount of survivin transcripts presented in cells. and HONE-1 cells are possibly due to increases in survivin gene transcription. Taken together, these results indicated that targeting Hsp90 with small molecule inhibitors might interfere with survivin gene transcription differently in different cancer cells.

\section{Targeting Hsp90 induces survivin expression through post- transcriptional mechanisms}

Since the above results revealed that changes at the level of gene transcription did not contribute to the increase of survivin protein in 17-AAG treated A549 cells, possible post-transcriptional mechanisms such as protein translation and $26 \mathrm{~S}$ proteasome-dependent protein degradation were investigated in this cell line. To determine whether 17-AAG induced over-expression of survivin through protein translation, translation inhibition study was performed. Human A549 cancer cells were pre-incubated with $500 \mathrm{nM}$ of cycloheximide for three hours and subsequently treated with various concentrations of 17-AAG for 24 hours. Cycloheximide is a translational inhibitor that exerts its effect by interfering with the translocation step in protein synthesis, thus blocking translational elongation. Western blot analysis revealed dose-dependent increases of survivin in the 17-AAG-treated A549 cancer cells (Figure 5A). Interestingly, cycloheximide treatment completely abolished the dose-dependent pattern of survivin expression in 17-AAG-treated cells (Figure 5A). However, the amount of survivin in cycloheximide/17-AAG co-treated cells did not decrease to the baseline level of the negative control (Figure 5A). These results suggest that 17-AAG induces over-expression of survivin in A549 cancer cells partially through the regulation of protein translation. Moreover, other posttranslational mechanisms may also contribute to the over-expression of survivin in 17-AAG-treated cells.

To determine whether 17-AAG may interfere with the stability of survivin protein in A549 cells, the rate of survivin protein degradation was determined in cells treated with/without 17-AAG. Cells were pre-incubated with 500 $\mathrm{nM}$ of cyclohexmide for one hour and subsequently coincubated with 17-AAG for various time. Western blot analysis revealed that the degradation rate of survivin protein was slightly slower in 17-AAG treated A549 cells than the untreated cells (Figure 5B). The amount of survivin protein presented in 17-AAG untreated-cells was reduced by $70 \%$ after $4 \mathrm{~h}$ of protein synthesis inhibition (Figure 5C). In contrast, the amount of survivin presented in 17-AAG-treated cells was reduced by only $20 \%$ at the same time point (Figure 5C). Thus, the reduced rate of protein degradation might also contribute to the increased amount of survivin protein presented in 17AAG treated A549 cancer cells. 
A

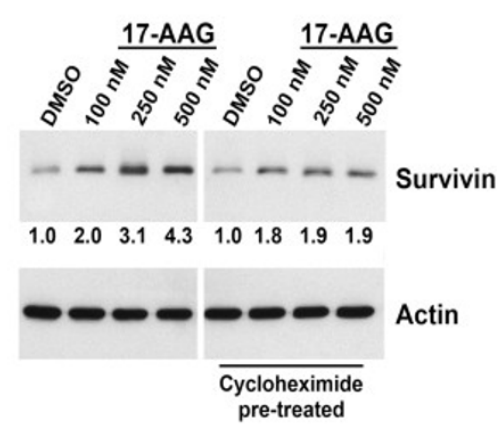

B

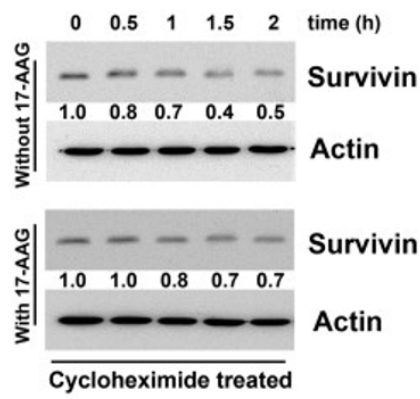

C

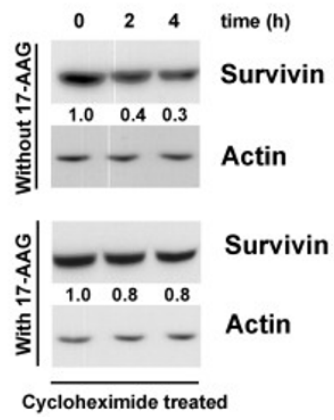

Figure $5 \mathrm{Hsp} 90$ inhibition induced over-expression of survivin through post-transcriptional mechanisms in A549 cells. (A) Hsp9O inhibition induced over-expression of survivin partially through the process of protein translation. A549 cells were pre-incubated with/ without $500 \mathrm{nM}$ of cycloheximide for 1 hour and subsequently treated with DMSO or various concentrations ( $100 \mathrm{nM}, 250 \mathrm{nM}$ and $500 \mathrm{nM}$ ) of 17-AAG 24 hours. The expression of survivin was revealed by Western blot analysis. Actin was used as an internal control. Relative ratio of expression was shown. (B) 17-AAG reduced the rate of survivin protein degradation in A549 cells. A549 cells were pre-incubated with 500 nM of cycloheximide for 1 hour and subsequently treated with/without $250 \mathrm{nM}$ of 17-AAG for various time. The expression of survivin was revealed by Western blot analysis. Actin was used as an internal control. Relative ratio of expression was shown. (C) The amount of survivin presented in un-treated A549 cells was less than that in 17-AAG-treated cells after 4 hours of protein synthesis inhibition. A549 cells were preincubated with $500 \mathrm{nM}$ of cycloheximide for 1 hour and subsequently treated with/without $250 \mathrm{nM}$ of $17-\mathrm{AAG}$ for 2 hours and 4 hours. The expression of survivin was revealed by Western blot analysis. Actin was used as an internal control. Relative ratio of expression was shown.
Targeting Hsp90 with 17-AAG reduces proteasomal activity in cancer cells

Survivin is normally degraded through the proteasomal degradation pathway and it has been shown that the $26 \mathrm{~S}$ proteasome is responsible for this process [26]. On the other hand, Hsp90 plays a role in the assembly and maintenance of the $26 \mathrm{~S}$ proteasome [20]. Furthermore, reduced proteasomal activity has been shown in 17-AAG and geldanamycin-treated cells [27,28]. Here, proteasome-dependent protein degradation pathway was investigated to determine whether proteasome plays a role in the reduced survivin degradation rate in 17-AAG treated A549, HONE-1 and HT-29 cells. In our study, Western blot analysis revealed that 17-AAG reduced the amount of $26 \mathrm{~S}$ proteasome presented in A549 cells (Figure 6A). In addition, proteasomal activity assay also revealed that the activity of $26 \mathrm{~S}$ proteasome was reduced by $25-30 \%$ in cells treated with 17-AAG (Figure 6B). To demonstrate that inhibition of $26 \mathrm{~S}$ proteasome would subsequently affect the amount of survivin expressed in cells, the $26 \mathrm{~S}$ proteasome inhibitor MG-132 was used. Western blot analysis clearly revealed that inhibition of the proteasomal activity by MG-132 induced survivin over-expression in a concentration-dependent manner (Figure 6C). Together with the results from the protein degradation experiment, these data suggest that increased survivin levels in A549 cells cannot simply be attributed to the induction of protein translation. Post-translational mechanisms such as the regulation of the $26 \mathrm{~S}$ proteasome-dependent protein degradation may also play a role in survivin over-expression in 17-AAG treated A549 cells.

To determine whether proteasomal activity was also affected in 17-AAG treated HT-29 and HONE-1 cells, proteasomal activity of drug-treated cells was measured. Proteasomal activity assay revealed that the activity of $26 \mathrm{~S}$ proteasome was reduced by $\sim 20 \%$ in HT-29 and HONE-1 cells treated with 17-AAG (Figure 7A). In addition, Western blot analysis revealed co-treatment of 17AAG and the proteasome inhibitor, MG-132, induced synergistic increases in the level of survivin present in both cell lines (Figure 7B). These results indicated that the inhibition of $26 \mathrm{~S}$ proteasome might also play a role in the up-regulation of survivin in 17-AAG treated HT-29 and HONE-1 cells.

\section{Targeting survivin increases drug sensitivity to 17-AAG in cancer cells}

It has been shown that silencing of survivin gene by small interfering RNAs produces supra-additive growth suppression in combination with 17-AAG in human prostate cancer cells [18]. To determine the functional importance of survivin in interfering with drug sensitivity to Hsp90 inhibitors in A549, HONE-1 and HT-29 cells, survivin was down-regulated by siRNA and cell viability was mea- 


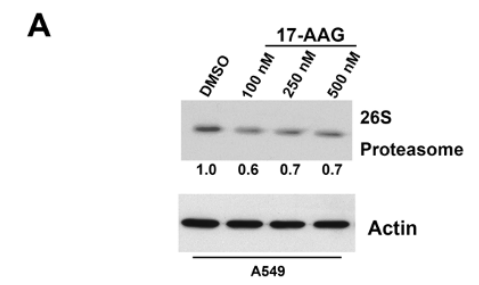

\section{B}

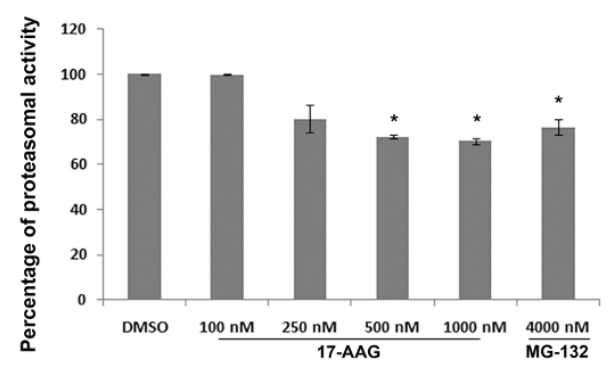

C

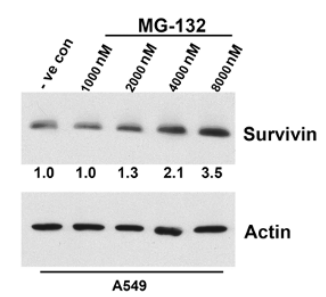

Figure 6 17-AAG interfered with the amount and activity of $26 \mathrm{~S}$ proteasome in A549 cells. (A) 17-AAG treatment reduced the amount of 265 proteasome presented in A549 cells. A549 cells were treated with DMSO and various concentrations (100 nM, $250 \mathrm{nM}$ and $500 \mathrm{nM}$ ) of 17-AAG for 24 hours. The expression of 265 proteasome was revealed by Western blot analysis. Actin was used as an internal control. Relative ratio of expression was shown. (B) Inhibition of Hsp90 with 17-AAG reduced proteasome activity in A549 cells. Cells were treated with various concentrations of 17-AAG and $4 \mu \mathrm{M}$ of MG-132 (positive control) for $24 \mathrm{~h}$. Cells were washed with PBS and lysed with TNESV buffer without protease inhibitor. Cell lysate were analyzed for proteasome activity using synthetic fluorogenic peptide succinyl-LeuLeu-Val-Tyr-7-amino-4-methylcoumarin. Statistical significance $(p<$ 0.05 ) between experimental samples and the DMSO control is denoted by "*". (C) Inhibition of 265 proteasome increased the amount of survivin in A549 cells. A549 cells were treated with DMSO and various concentrations (1000 nM, $2000 \mathrm{nM}, 4000 \mathrm{nM}$ and $8000 \mathrm{nM}$ ) of the $26 \mathrm{~S}$ proteasome inhibitor, MG-132, for 24 hours. The expression of survivin was revealed by Western blot analysis. Actin was used as an internal control. Relative ratio of expression was shown.

sured by MTT assay. Cells were treated with survivinspecific siRNA oligomer (siR-S) or scramble oligomer (siR-C) for $48 \mathrm{~h}$ and sub-subsequently incubated with/ without $250 \mathrm{nM}$ of $17-\mathrm{AAG}$ for $24 \mathrm{~h}$. Cells viability assay revealed that A549, HT-29 and HONE-1 cells treated with $250 \mathrm{nM}$ of 17-AAG did not show reduced viability as compared to cells treated with DMSO (Figure 8). In addi-
A

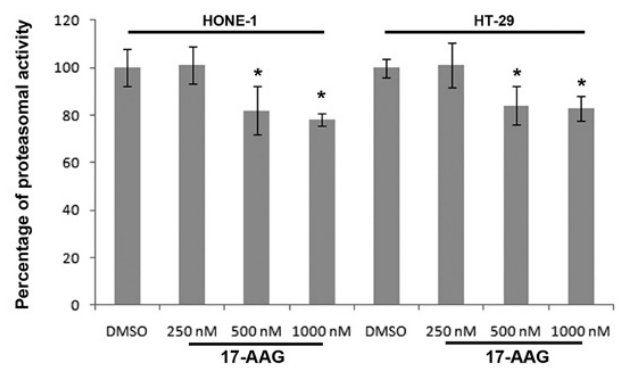

B

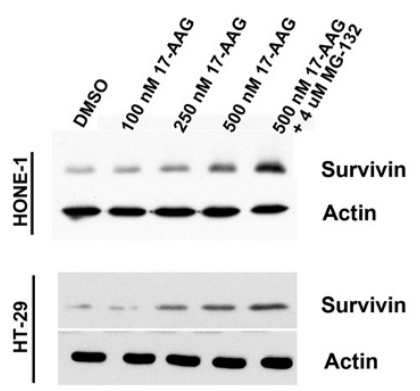

Figure 7 Inhibition of Hsp90 with 17-AAG reduced proteasome activity in HONE-1 and HT-29 cells. (A) Cells were treated with various concentrations of 17-AAG for $24 \mathrm{~h}$. Cells were washed with PBS and lysed with TNESV buffer without protease inhibitor. Cell lysate were analyzed for proteasome activity using synthetic fluorogenic peptide succinyl-Leu-Leu-Val-Tyr-7-amino-4-methylcoumarin. Statistical significance $(p<0.05)$ between experimental samples and the DMSO control is denoted by "*". (B) Inhibition of 265 proteasome further increased the amount of survivin protein in 17-AAG treated HONE-1 and HT-29 cells. Cells were treated with DMSO and various concentrations (100 nM, 250 nM, 500 nM) of 17-AAG with/without MG132 for 24 hours. The expression of survivin was revealed by Western blot analysis. Actin was used as an internal control.

tion, down-regulation of survivin by siR-S significantly reduced cell viability by $\sim 30 \%$ in both cell lines as compared to cells transfected with control oligomer, siR-C (Figure 8). Interestingly, siR-S/17-AAG combination treatment further reduced the cell viability of A549, HT29 and HONE-1 as compared to 17-AAG mono-treatment (Figure 8). Taken together, our results indicate that survivin plays an important role in the sensitivity to the Hsp90 inhibitor, 17-AAG, in our tested cancer cell lines.

\section{Discussion}

It is widely believed that targeting Hsp90 with small molecule inhibitors is able to directly interfere with the physical interaction between Hsp90 and survivin, leading to the decrease of survivin protein level and induction of cancer cell death $[5,15]$. Interestingly, this study demonstrated for the first time that targeting Hsp90 with small 


\section{A}

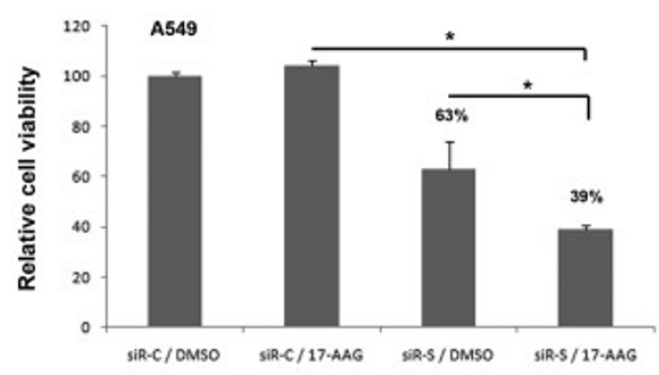

B

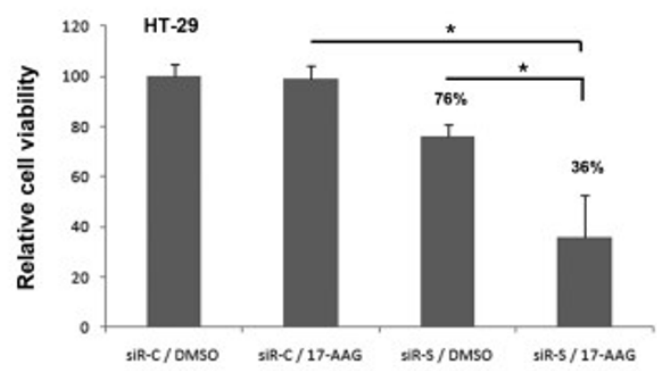

C

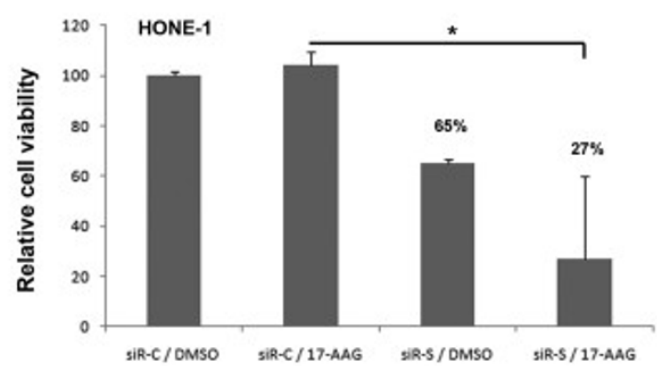

Figure 8 Down-regulation of survivin enhanced the sensitivity to Hsp90 inhibitor in various cancer cells. A549 (A), HT-29 (B) and HONE-1 (C) cells were transfected with siR-C (scramble control) and siR-S (survivin specific) siRNA oligomers for $48 \mathrm{~h}$ and subsequently incubated with/without $250 \mathrm{nM}$ of 17-AAG for $24 \mathrm{~h}$. MTT cell viability assay was used to determine the viability of various treatments treated cells. Statistical significance $(p<0.05)$ between experimental samples is denoted by "*".

molecule inhibitors will affect the expression of survivin at various stages, resulting in an increase of the amount of survivin protein presented in cancer cells. Furthermore, this study demonstrated that survivin plays an important role in the sensitivity to the Hsp90 inhibitor, 17-AAG, in cancer cells.

Here, we showed that targeting Hsp90 with small molecule inhibitor affected the amount of survivin mRNA transcript presented in cancer cells. It is not surprising that targeting Hsp90 induces different effect at the level of gene transcription in different cancer cells. Literatures revealed that the rate of survivin gene transcription is positively regulated by molecules such as sp1, sp3 and Myc $[29,30]$. In contrast, the gene transcription process of survivin is negatively regulated by molecules such as $\mathrm{p} 53$, retinoblastoma $(\mathrm{Rb})$ and prostate-derived Ets transcription factor (PDEF) [31-33]. Importantly, Hsp90 interferes with sp1, sp3, p53 and $\mathrm{Rb}$ simultaneously $[34,35]$. Hence, differences in the response of survivin gene transcription may reflect different dependencies of various Hsp90-interfered and Hsp90-unrelated transcriptional factors on the expression of survivin in different cell types. Therefore, depending on the cellular context, targeting Hsp90 might indirectly up-regulate/down-regulate the process of survivin gene transcription through the interference with various survivin-related transcriptional factors.

Interestingly, our data also demonstrated that decreases at the mRNA level did not translate into decreases in survivin protein level in 17-AAG treated A549 cells. Together with results from the translation inhibition experiment, the protein degradation experiment and the examination of the survivin-related $26 \mathrm{~S}$ proteasome, the current study strongly indicates that Hsp90 also interferes with survivin expression at the post-transcriptional level. Thus, Hsp90-targeted treatment interferes with the process of survivin gene transcription, protein translation and protein degradation simultaneously. In fact, Hsp90 plays an important role in the assembly and maintenance of the $26 \mathrm{~S}$ proteasome $[20,36]$. The activity of $26 \mathrm{~S}$ proteasome was shown to be reduced by the addition of the Hsp90 inhibitor, geldanaymicin, in vitro [20]. Reduced proteasomal activity was also shown previously in Hsp90inhibited multiple myeloma cells [27]. On the other hand, previous studies demonstrated that indomethacin (NASID) and chlamydocin (HDAC inhibitor) enhanced survivin degradation through ubiquitin proteasome machinery in cells $[37,38]$. In our study, the use of proteasome inhibitor MG-132 was shown effective in increasing the amount of survivin present in our tested cancer cell lines, indicating that the activity of proteasome was important for survivin regulation. Therefore, the level of activity of proteasome might be one of the determinants of the amount of survivin present in Hsp90-inhibited cancer cells. However, it is hard to determine whether the interference with proteasome plays the most important role in the up-regulation of survivin. Further investigations are needed to determine the relative importance of transcription, translation and proteasome-related protein degradation in different Hsp90-targeted cancer cells. It is also worth noting that both 17-AAG and geldanamycin treatment reduced the amount of survivin presented in HeLa cells and this result was consistent with other studies. In contrast, results of the 3D-culture model revealed that 17-AAG treatment $(1 \mu \mathrm{M})$ was also able to induce the over-expression of survivin in three dimensional cul- 
tured A549, HONE-1 and HT-29 cells (Additional file 1). Thus, the current study indicates that targeting Hsp90 may induce cell line-specific responses in the expression of survivin.

Importantly, results of the current study raise the concern that Hsp90 inhibitors might not function in a way as we previously thought. Indeed, literature reported that 17-AAG promoted formation of osteolytic lesions and bone metastases in murine breast cancer model, even though the drug reduced tumor growth at the orthotopic site [39]. Furthermore, Kayani et al. demonstrated that 17-AAG treatment was able to enhance the expression of Hsp70 in $\mathrm{C} 2 \mathrm{C} 12$ muscle fiber cells and the recovery of extensor digitorum longus (EDL) following lengthening contraction-induced damage in animal model [40]. Thus, targeting Hsp90 with small molecular inhibitors may not be able to induce cell death in certain circumstances.

\section{Conclusion}

In conclusion, the current study reveals the complex interaction between Hsp90 and survivin in cancer cells. Besides stabilizing the survivin protein through simple physical interaction, Hsp90 also indirectly interferes with survivin expression through transcription, translation and proteasome-related protein degradation. These novel findings suggest a model in which gene transcription, together with protein translation and proteasomal degradation, constitute a platform capable of modulating the amount of survivin expressed in Hsp90-targeted cancer cells. Our findings suggest that down-regulation of survivin is not a definitive therapeutic function of Hsp90 inhibitors and that dual inhibition of Hsp90 and survivin may be warranted.

\section{Materials and methods \\ Cell lines, antibodies and reagents}

The human lung carcinoma (A549), nasopharyngeal carcinoma (HONE-1) and colorectal adenocarcinoma (HT29) cells were purchased from the American Type Culture Collection (ATCC, Manassas, VA). A549 cells were cultured in RPMI 1640 medium (Gibco, Grand Island, $\mathrm{NY}$ ), supplemented with $10 \%$ fetal bovine serum, penicillin $(100 \mathrm{U} / \mathrm{mL})$, streptomycin $(100 \mu \mathrm{g} / \mathrm{mL})$ and L-glutamine $(0.29 \mathrm{mg} / \mathrm{mL})$, at $37^{\circ} \mathrm{C}$. HONE-1 and HT-29 cells were cultured in RPMI 1640 medium (Gibco, Grand Island, NY), supplemented with $5 \%$ fetal bovine serum, penicillin $(100 \mathrm{U} / \mathrm{mL})$, streptomycin $(100 \mu \mathrm{g} / \mathrm{mL})$ and Lglutamine $(0.29 \mathrm{mg} / \mathrm{mL})$, at $37^{\circ} \mathrm{C}$. The antibodies used in this study included a mouse anti-Actin antibody (Santa Cruz Biotechnology, Santa Cruz, CA), a rabbit anti-Survivin antibody (R\&D Systems, Minneapolis, MN), a rabbit anti-Akt antibody (Cell Signaling Technology, Danvers, MA) and a mouse anti-26S proteasome antibody (abcam, Cambridge, UK). Hsp90 inhibitors used in this study included: 17-AAG (Calbiochem, Darmstadt, Germany), geldanamycin (Calbiochem, Darmstadt, Germany) and cycloheximide (Calbiochem, Darmstadt, Germany).

\section{Real-time reverse transcription-polymerase chain reaction (Real-time PCR)}

Expression level of survivin transcript was determined by real-time reverse transcriptase (RT)-polymerase chain reaction (PCR) using a LightCycler instrument (Roche, Indianapolis, IN). Primers and Taqman probes were designed by Probe Finder ${ }^{\text {tw }}$ http://www.universalprobelibrary.com. Taqman probes were from the Universal Probe Library: survivin and hGAPDH. Specific primers with following sequences were used: survinin forward, 5 GCCCAGTGTTTCTTCTGCTT; Survivin reverse, 5'CC GGACGAATGCTTTTTATG; hGAPDH forward, 5' AG CCACATCGCTCAGACAC and hGAPDH reverse, 5' G CCCAATACGACCAAATCC. The real-time PCR condition was as follows: 1 cycle of initial denaturation at $95^{\circ} \mathrm{C}$ for $10 \mathrm{~min}, 45$ cycles of amplification at $95^{\circ} \mathrm{C}$ for $10 \mathrm{~s}$, $60^{\circ} \mathrm{C}$ for $30 \mathrm{~s}$, and $72^{\circ} \mathrm{C}$ for $1 \mathrm{~s}$, with a single fluorescence acquisition. hGAPDH gene was used as an internal control. All experiments have been repeated twice.

\section{SDS-PAGE and Western blot analysis}

Cells were lysed with ice-cold lysis buffer $(10 \mathrm{mM}$ Tris, 1 $\mathrm{mM}$ EDTA, $1 \mathrm{mM}$ DTT, $60 \mathrm{mM} \mathrm{KCl}, 0.5 \% \mathrm{NP}-40$ and protease inhibitors). Total cell lysates, fractions of supernatant or pellet were resolved on $10 \%$ and $12 \%$ polyacrylamide SDS gels under reducing conditions. The resolvedproteins were electrophoretically transferred to PVDF membranes (Amersham Life Science, Amersham, U.K.) for Western blot analysis. The membranes were blocked with $5 \%$ non-fat milk powder at room temperature for two hours, washed twice with PBST (1\% Tween) and then incubated with primary antibody for 90 minutes at room temperature. The membranes were washed twice with PBST then subsequently incubated with a horseradish peroxidase-conjugated secondary antibody (dilution at 1:10000, Santa Cruz Biotechnology, Santa Cruz, CA). Immunoreactivity was detected by Enhanced Chemiluminescence (Amersham International, Buckingham, U.K.) and autoradiography. All experiments have been repeated twice.

\section{Proteasome activity assay}

Cells exposed to various concentrations of 17-AAG and MG-132 for $24 \mathrm{~h}$ were washed twice with PBS and lysed with TNESV buffer [50 mM Tris- $\mathrm{HCl}$ (pH 7.5), 1\% NP40 detergent, $2 \mathrm{mM}$ EDTA, $100 \mathrm{mM} \mathrm{NaCl}, 10 \mathrm{mM}$ sodium orthovanadate] without protease inhibitors. Cell lysate were assayed for proteasome chymotrypsin activity using the synthetic fluorogenic peptide chymotrypsin substrate, N-Succinyl-Leu-Leu-Val-Tyr-AMC. Fluorescent 
signals were measured with a 96-well plate reader with an excitation wavelength of $380 \mathrm{~nm}$ and emission wavelength of $460 \mathrm{~nm}$. All experiments have been performed as triplicate and repeated twice.

\section{siRNA}

Target-validated siRNA oligos (Santa Cruz Biotechnology, Santa Cruz, CA) were transfected into cells using the Lipofectamine-2000 reagent (Invitrogen, Carlsbad, CA). Briefly, cells were seeded onto 96-well plates or chamberslides, and cultured overnight in $100 \mu \mathrm{l}$ of antibiotic-free RPMI media. siRNA oligomers $(8 \mathrm{pmol}$ in $0.4 \mu \mathrm{l})$ were diluted in $25 \mu \mathrm{l}$ of Opti-MEM I medium (Invitrogen, Carlsbad, CA) without serum, and then mixed with $0.2 \mu \mathrm{l}$ of Lipofectamine-2000 transfection reagent for $25 \mathrm{~min}$ at room temperature. Cells were overlaid with the transfection mixture, and incubated for various times.

\section{MTT cell viability assay}

Cells seeded onto 96-well plates were transfected with/ without survivin-specific siRNA oligomer for $48 \mathrm{~h}$ and subsequently treated with 17-AAG for $24 \mathrm{~h}$. $25 \mu \mathrm{l}$ of MTT $(5 \mathrm{mg} / \mathrm{mL}$ ) was added to each sample and incubated for 4 hours, under $5 \% \mathrm{CO}_{2}$ and $37^{\circ} \mathrm{C} .100 \mu \mathrm{l}$ of lysis buffer $(20 \%$ SDS, 50\% DMF) was subsequently added into each sample and further reacted for 16 hours.

\section{Authors' information}

C. H. A. Cheung, Ph.D. (Post-doctoral research fellow, molecular biologist)

H. H. Chen, Ph.D. (Post-doctoral research fellow, molecular biologist)

L.T. Cheng, Ph.D. (Post-doctoral research fellow, molecular biologist)

K.W. Lyu, M.Sc. (Research student)

J.R. Kanwar, Ph.D. (Principle investigator, Assistance professor, molecular biologist)

J. Y. Chang, M.D. (Distinguished investigator, Professor, medical oncologist)

\section{Additional material}

Additional file 1 17-AAG treatment induced the over-expression of survivin in three-dimensionally cultured A549, HONE-1 and HT-29 cells. HeLa, A549, HONE-1 and HT-29 cells were three-dimensionally cultured in the RPMI/Matrigel ${ }^{\circ}$ matrix for five days and subsequently treated with $1 \mu \mathrm{M}$ of 17-AAG for 24 hours. Expression of survivin was analyzed by Western blot analysis. (A) Various 3D-cultured cancer cells were shown by light microscopy. (B) Western blot analysis revealed that 17-AAG treatment induced the over-expression of survivin in 3D-cultured A549, HONE-1 and HT-29 cells. In contrast, the same treatment reduced the expression of survivin in HeLa cells.

\section{Abbreviations}

17-AAG: 17-(Allylamino)-17-demethoxygeldanamycin; Hsp90: heat-shock protein 90; siR-C: scramble siRNA oligos; siR-S: survivin-targeted siRNA oligos.

\section{Competing interests}

The authors declare that they have no competing interests.

\section{Authors' contributions}

$\mathrm{CHAC}$ performed most of the in vitro studies and drafted the manuscript. $\mathrm{HHC}$ performed the quantitative RT-PCR analysis. LTC participated in sample preparation and also revised the manuscript. KWL participated in sample preparation and a few preliminary experiments. JRK provided HeLa cells and re-confirmed some of the experimental results. JYC coordinated the study. All authors read and approved the final manuscript.

\section{Acknowledgements}

This work was supported by intramural grants NSC98-2323-B-400-004 from the National Science Council, Taiwan R.O.C.; DOH99-TD-C-111-004 from the Department of Health, Taiwan R.O.C. and CA-097-PP-02 from the National Health Research Institutes, R.O.C.

\section{Author Details}

1National Institute of Cancer Research, National Health Research Institutes (NHRI), Tainan 70456, Taiwan ROC, 2Department of Biological Science, University of Southern California, California, USA, 3Institute of Biotechnology (BioDeakin), Institute for Technology Research and Innovation, Deakin University, Geelong, Victoria 3217, Australia and ${ }^{4}$ Division of Hematology and Oncology, Department of Internal Medicine, National Cheng Kung University Hospital, Tainan 70456, Taiwan ROC

Received: 5 January 2010 Accepted: 15 April 2010

Published: 15 April 2010

\section{References}

1. Becker B, Multhoff G, Farkas B, Wild PJ, Landthaler M, Stolz W, Vogt T: Induction of $\mathrm{Hsp} 90$ protein expression in malignant melanomas and melanoma metastases. Exp Dermatol 2004, 13:27-32.

2. Wu X, Wanders A, Wardega P, Tinge B, Gedda L, Bergstrom S, Sooman L, Gullbo J, Bergqvist M, Hesselius P, et al.: Hsp90 is expressed and represents a therapeutic target in human oesophageal cancer using the inhibitor 17-allylamino-17-demethoxygeldanamycin. Br J Cancer 2009, 100:334-343.

3. Gallegos Ruiz MI, Floor K, Roepman P, Rodriguez JA, Meijer GA, Mooi WJ, Jassem E, Niklinski J, Muley T, van Zandwijk N, et al:: Integration of gene dosage and gene expression in non-small cell lung cancer, identification of HSP90 as potential target. PLoS One 2008, 3:e0001722.

4. Ogata M, Naito Z, Tanaka S, Moriyama Y, Asano G: Overexpression and localization of heat shock proteins mRNA in pancreatic carcinoma. $J$ Nippon Med Sch 2000, 67:177-185.

5. Fortugno P, Beltrami E, Plescia J, Fontana J, Pradhan D, Marchisio PC, Sessa WC, Altieri DC: Regulation of survivin function by Hsp90. Proc Natl Acad Sci USA 2003, 100:13791-13796.

6. Citri A, Gan J, Mosesson Y, Vereb G, Szollosi J, Yarden Y: Hsp90 restrains ErbB-2/HER2 signalling by limiting heterodimer formation. EMBO Rep 2004, 5:1165-1170.

7. Meli M, Pennati M, Curto M, Daidone MG, Plescia J, Toba S, Altieri DC, Zaffaroni N, Colombo G: Small-molecule targeting of heat shock protein 90 chaperone function: rational identification of a new anticancer lead. J Med Chem 2006, 49:7721-7730.

8. Zaffaroni N, Daidone MG: Survivin expression and resistance to anticancer treatments: perspectives for new therapeutic interventions. Drug Resist Updat 2002, 5:65-72.

9. Cheung $\mathrm{CH}$, Chen $\mathrm{HH}$, Kuo CC, Chang $\mathrm{CY}$, Coumar MS, Hsieh HP, Chang $J Y:$ Survivin counteracts the therapeutic effect of microtubule destabilizers by stabilizing tubulin polymers. Mol Cancer 2009, 8:43.

10. Moriai R, Tsuji N, Moriai M, Kobayashi D, Watanabe N: Survivin plays as a resistant factor against tamoxifen-induced apoptosis in human breast cancer cells. Breast Cancer Res Treat 2009, 117:261-271.

11. Jiang G, Ren B, Xu L, Song S, Zhu C, Ye F: Survivin may enhance DNA double-strand break repair capability by up-regulating Ku70 in human KB cells. Anticancer Res 2009, 29:223-228.

12. Nakamura M, Tsuji N, Asanuma K, Kobayashi D, Yagihashi A, Hirata K Torigoe T, Sato N, Watanabe N: Survivin as a predictor of cisdiamminedichloroplatinum sensitivity in gastric cancer patients. Cancer Sci 2004, 95:44-51. 
13. Rodel F, Hoffmann J, Distel L, Herrmann M, Noisternig T, Papadopoulos T, Sauer R, Rodel C: Survivin as a radioresistance factor, and prognostic and therapeutic target for radiotherapy in rectal cancer. Cancer Res 2005, 65:4881-4887.

14. Seo SI, Gera L, Zhau HE, Qian WP, Iqbal S, Johnson NA, Zhang S, Zayzafoon $M$, Stewart J, Wang R, et al:: BKM an acyl-tyrosine bisphosphonate amide derivative, inhibits the bone metastatic growth of human prostate cancer cells by inducing apoptosis. Clin Cancer Res 1740, 14:6198-6206.

15. Pennati M, Folini M, Zaffaroni N: Targeting survivin in cancer therapy: fulfilled promises and open questions. Carcinogenesis 2007, 28:1133-1139

16. Gyurkocza B, Plescia J, Raskett CM, Garlick DS, Lowry PA, Carter BZ, Andreeff M, Meli M, Colombo G, Altieri DC: Antileukemic activity of shepherdin and molecular diversity of hsp90 inhibitors. J Natl Cancer Inst 2006, 98:1068-1077.

17. Siegelin MD, Habel A, Gaiser T: 17-AAG sensitized malignant glioma cells to death-receptor mediated apoptosis. Neurobiol Dis 2009, 33:243-249.

18. Paduano F, Villa R, Pennati M, Folini M, Binda M, Daidone MG, Zaffaroni N Silencing of survivin gene by small interfering RNAs produces supraadditive growth suppression in combination with 17-allylamino-17demethoxygeldanamycin in human prostate cancer cells. Mol Cancer Ther 2006, 5:179-186.

19. Wang S-a, Hung J-J: Hsp90 localized with Sp1 in mitosis involves in Sp1 stability. FASEB J 2008, 22:832-838.

20. Imai J, Maruya M, Yashiroda H, Yahara I, Tanaka K: The molecular chaperone $\mathrm{Hsp90}$ plays a role in the assembly and maintenance of the 26S proteasome. EMBO J 2003, 22:3557-3567.

21. Ohba S, Hirose Y, Yoshida K, Yazaki T, Kawase T: Inhibition of 90-kD heat shock protein potentiates the cytotoxicity of chemotherapeutic agents in human glioma cells. J Neurosurg 2009.

22. Modi S, Stopeck AT, Gordon MS, Mendelson D, Solit DB, Bagatell R, Ma W, Wheler J, Rosen N, Norton L, et al.: Combination of trastuzumab and tanespimycin (17-AAG, KOS-953) is safe and active in trastuzumabrefractory HER-2 overexpressing breast cancer: a phase I doseescalation study. J Clin Oncol 2007, 25:5410-5417.

23. Babchia N, Calipel A, Mouriaux F, Faussat AM, Mascarelli F: 17-AAG and 17-DMAG-induced inhibition of cell proliferation through B-Raf downregulation in WT B-Raf-expressing uveal melanoma cell lines. Invest Ophthalmol Vis Sci 2008, 49:2348-2356.

24. Tse AN, Klimstra DS, Gonen M, Shah M, Sheikh T, Sikorski R, Carvajal R, Mui J, Tipian C, O'Reilly E, et al:: A phase 1 dose-escalation study of irinotecan in combination with 17-allylamino-17-demethoxygeldanamycin in patients with solid tumors. Clin Cancer Res 2008, 14:6704-6711.

25. Kawakami H, Tomita M, Okudaira T, Ishikawa C, Matsuda T, Tanaka Y, Nakazato T, Taira N, Ohshiro K, Mori N: Inhibition of heat shock protein90 modulates multiple functions required for survival of human T-cell leukemia virus type I-infected T-cell lines and adult T-cell leukemia cells. Int J Cancer 2007, 120:1811-1820.

26. Zhao J, Tenev T, Martins LM, Downward J, Lemoine NR: The ubiquitinproteasome pathway regulates survivin degradation in a cell cycledependent manner. J Cell Sci 2000, 113(Pt 23):4363-4371.

27. Mitsiades CS, Mitsiades NS, McMullan CJ, Poulaki V, Kung AL, Davies FE, Morgan G, Akiyama M, Shringarpure R, Munshi NC, et al:: Antimyeloma activity of heat shock protein-90 inhibition. Blood 2006, 107:1092-1100.

28. Cane S, Das R, Ponnappan S, Ponnappan U: Contribution of HSP90 to the proteasomal dysfunction accompanying immune senescence. $J$ Immunol 2009, 182:14-35.

29. Xu R, Zhang P, Huang J, Ge S, Lu J, Qian G: Sp1 and Sp3 regulate basal transcription of the survivin gene. Biochem Biophys Res Commun 2007, 356:286-292.

30. Li H, Wei Y, Tan Y, Wu X: Myc upregulates anti-apoptotic protein, Survivin via a transcriptional activation. FASEB J 2008, 22:631-637

31. Raj D, Liu T, Samadashwily G, Li F, Grossman D: Survivin repression by p53, Rb and E2F2 in normal human melanocytes. Carcinogenesis 2008, 29:194-201.

32. Hoffman WH, Biade S, Zilfou JT, Chen J, Murphy M: Transcriptional repression of the anti-apoptotic survivin gene by wild type p53. J Biol Chem 2002, 277:3247-3257.

33. Ghadersohi A, Pan D, Fayazi Z, Hicks DG, Winston JS, Li F: Prostate-derived Ets transcription factor (PDEF) downregulates survivin expression and inhibits breast cancer cell growth in vitro and xenograft tumor formation in vivo. Breast Cancer Res Treat 2007, 102:19-30.
34. Muller L, Schaupp A, Walerych D, Wegele H, Buchner J: Hsp90 regulates the activity of wild type $\mathrm{p} 53$ under physiological and elevated temperatures. J Biol Chem 2004, 279:48846-48854.

35. Wang SA, Chuang JY, Yeh SH, Wang YT, Liu YW, Chang WC, Hung JJ: Heat shock protein 90 is important for Sp1 stability during mitosis. $\mathrm{J}$ Mol Biol 2009, 387:1106-1119.

36. Yamano T, Mizukami S, Murata S, Chiba T, Tanaka K, Udono H: Hsp90mediated assembly of the $26 \mathrm{~S}$ proteasome is involved in major histocompatibility complex class I antigen processing. $\mathrm{J}$ Biol Chem 2008, 283:28060-28065.

37. Chiou SK, Mandayam S: NSAIDs enhance proteasomic degradation of survivin, a mechanism of gastric epithelial cell injury and apoptosis. Biochem Pharmacol 2007, 74:1485-1495.

38. De Schepper S, Bruwiere H, Verhulst T, Steller U, Andries L, Wouters W, Janicot M, Arts J, Van Heusden J: Inhibition of histone deacetylases by chlamydocin induces apoptosis and proteasome-mediated degradation of survivin. J Pharmacol Exp Ther 2003, 304:881-888.

39. Price JT, Quinn JM, Sims NA, Vieusseux J, Waldeck K, Docherty SE, Myers D, Nakamura A, Waltham MC, Gillespie MT, Thompson EW: The heat shock protein 90 inhibitor, 17-allylamino-17-demethoxygeldanamycin, enhances osteoclast formation and potentiates bone metastasis of a human breast cancer cell line. Cancer Res 2005, 65:4929-4938.

40. Kayani AC, Close GL, Broome CS, Jackson MJ, McArdle A: Enhanced recovery from contraction-induced damage in skeletal muscles of old mice following treatment with the heat shock protein inducer 17(allylamino)-17-demethoxygeldanamycin. Rejuvenation Res 2008, 11:1021-1030

doi: 10.1186/1476-4598-9-77

Cite this article as: Cheung et al., Targeting Hsp90 with small molecule inhibitors induces the over-expression of the anti-apoptotic molecule, survivin, in human A549, HONE-1 and HT-29 cancer cells Molecular Cancer 2010, 9:77

\section{Submit your next manuscript to BioMed Central and take full advantage of:}

- Convenient online submission

- Thorough peer review

- No space constraints or color figure charges

- Immediate publication on acceptance

- Inclusion in PubMed, CAS, Scopus and Google Scholar

- Research which is freely available for redistribution 